\title{
Full Scaled Numerical Simulation of the Critical Velocity in Sloping Tunnels during the High Load Fire Incidents
}

\author{
Mehdi Rafiei \\ Department of Mechanical Engineering, Semnan Branch, Islamic Azad University, Semnan, Iran \\ Institute of Internal Combustion Engines and Thermodynamics, Graz University of Technology, Graz, Austria
}

\begin{abstract}
Fire safety is considered as one of the major objectives in design, construction and specially tunnel operation. The hot and toxic smoke propagation is a fundamental reason of human losses during a fire inside the tunnels. Therefore, an exact analytical investigation on the probable fire scenarios and its destructive effects for passengers, vehicles and structure are the main part of the tunnel safety measures. The complications of tunnel fires can be reduced, using a suitable hot smoke management regime through the standard safety plan.

In a unidirectional traffic tunnel, upstream of the fire is usually a place where people and vehicles are trapped and can leave the tunnel during a fire only via egress ways. Meanwhile, downstream the fire people and vehicles in most cases will have a chance to leave the tunnel. In order to have a full view of the problem and to find a proper solution, numerous effective parameters in smoke control and temperature distribution have to be considered in design phases. A sufficient longitudinal air speed is one of the most important parameters in the hot smoke management. Mentioned longitudinal airflow creates a safe place upstream the fire through preventing smoke back-layering from the location of the fire.
\end{abstract}

The critical velocity is known as a required volume flow to prevent smoke back-layering from the location of the fire. The mentioned critical velocity is influenced by the heat release rate (HRR) of the fire, tunnel slope and structural characteristics. The implementation of small size fire tests is an easy and cheap way to see the performance of safety installations, smoke back-layering, and airflow and temperature distributions. However, as in most cases a fullscale fire tests is not easily feasible, CFD simulations can be a great opportunity to investigate the tunnel ventilation in a fire incident.

In this numerical study, CFD simulation is employed, to demonstrate the effect of the required critical velocity during the fire with high heat release rates, in a tunnel with different longitudinal slopes. The results are compared with other experimental data and numerical studies.

\section{Keywords}

Tunnel ventilation, Smoke distribution, Critical velocity,

Numerical simulation

\section{INTRODUCTION}

The quality of smoke propagation during a fire is a crucial concern of ventilation design for tunnels. Smoke control is a basic objective for ventilation to evacuate hot smoke and create sufficient time and place for rescue activities. Many experimental and numerical studies are carried out to show the quality of the smoke propagation in the tunnel with longitudinal ventilation system [1-8]. The result of such studies confirmed the effect of some key parameters like tunnel geometry, especially longitudinal slope, heat release rate of the fire and air speed, in smoke and temperature distributions [9-18].

H.Y.wang has investigated, numerically and theoretically, the influence of the longitudinal air velocity on smoke and temperature propagation in the various elevation of the tunnel cross section [9]. L.Yi et al. have conducted a group of fire tests in a model scale to show the effect of the air velocity in the temperature profiles and back-layering over the tunnel length [3]. Atkinson and $\mathrm{Wu}$ have performed an experimental study in the model scale to show the critical velocity correlation factor and related temperature profiles in sloping tunnels with range of 0 to $10^{\circ}$ [16]. In the other model scale experimental study, Liang Yi et al. have investigated the critical velocity correlation factor in sloping tunnels in a range of 0 to $\pm 3 \%$ [10].

This numerical simulation study, in fact, will follow the works that carried out by Atkinson \& Wu [16] and Liang Yi et al. [10]. The numerical investigation will focus on simulation of critical velocity in the tunnel with longitudinal slope range of 0 to $\pm 3 \%$ and fire heat release rate of 29.1 and 20MW. The correlation factor for critical velocity for mentioned fire load and tunnel gradients will be compared with result of the scale models.

\section{THEORETICAL CALCULATION OF THE CRITICAL VELOCITY}

As previously mentioned, a proper longitudinal air velocity during a fire incident, which is called critical velocity, will prevent smoke back-layering from the location of the fire. Various theoretical and experimental approaches are presented to determine the critical velocity $[11,12,17$, and 18]. In this study, Kang's approach is employed for verification of the archived critical velocities from the numerical simulations $[17,18]$. The mentioned verification is only used for positive slopes. The longitudinal critical velocity can be calculated for the equations 1,2 . 
$V_{c}=K_{g}\left(\frac{g H_{D} \dot{Q}}{F r_{c} \rho_{0} C_{p} A T_{f}}\right)^{\frac{1}{3}}$

$\mathrm{T}_{\mathrm{f}}=\frac{\dot{\mathrm{Q}}}{\rho_{0} \mathrm{C}_{\mathrm{p}} \mathrm{AV}}+\mathrm{T}_{0}$

Where, $\dot{Q}$ is heat release rate $(\mathrm{kW}), \mathrm{V}_{\mathrm{c}}$ is critical velocity $(\mathrm{m} / \mathrm{s})$, A is tunnel cross section $\left(\mathrm{m}^{2}\right), \mathrm{H}_{\mathrm{D}}$ is hydraulic diameter of the tunnel cross section $(\mathrm{m}), \mathrm{T}_{\mathrm{f}}, \mathrm{T}_{0}$ are the average downstream and ambient temperature, respectively $(\mathrm{K}), \mathrm{C}_{\mathrm{p}}$ is the specific heat capacity of the air $(\mathrm{kJ} / \mathrm{kg} \mathrm{K}), \rho_{0}$ is the ambient air density $\left(\mathrm{kg} / \mathrm{m}^{3}\right)$, $\mathrm{g}$ is the gravitational acceleration $\left(\mathrm{m} / \mathrm{s}^{2}\right)$ and $\mathrm{Fr}_{\mathrm{c}}$ is critical Froude number 4.5 for high fire loads and eventually $\mathrm{K}_{\mathrm{g}}$, gradient factor, can be calculated from the equation 3 .

$\mathrm{K}_{\mathrm{g}}=1+0.0374 \times(\theta)^{0.8}$

Where, $\theta$ represent the slope of the tunnel in percentage.

\section{NUMERICAL MODEL AND BOUNDARY CONDITIONS}

Fire dynamics simulator (FDS) is used in several studies to simulate numerically fires in the tunnel to show the smoke and air velocity behavior. The open source FDS code solves thermally driven Naiver-Stokes equations. Various numerical investigations with support of experimental studies have been implemented to verify the software performance and evaluation documentations are available [21, 22]. Certainly, with an appropriate boundary definition, especially suitable mesh sizes and also results verification assessments, acceptable outcomes can be expected from the numerical simulations. However, in order to prove the results, theoretical and experimental evaluations are scientifically proven approaches and are necessary for verification.

In this way, in the current study, CFD model is taken from [10] to create the possibility of result assessments. Figure 1 depicts the tunnel cross section in a real scale. Experimental and numerical investigations about the critical velocity and temperature distribution have been carried out in model scale $(1 / 10)$ [10, 17]. Therefore, the results of the mentioned experimental studies can be used to evaluate CFD simulations with respect to the scale-laws in tunnel ventilation in terms of the fire.

The critical velocity and heat release rate can be converted to full or scale model using previously achieved laws (Quintiere 1989 [22]). Equation 4 presents a mathematical relation between ratio of the velocity and tunnel length in full and model scales. Equation 5 shows same relation between heat release rate and tunnel length (Froude modeling).

$\frac{\mathrm{U}_{\mathrm{M}}}{\mathrm{U}_{\mathrm{F}}}=\left(\frac{\mathrm{L}_{\mathrm{M}}}{\mathrm{L}_{\mathrm{F}}}\right)^{1 / 2}$

$\frac{\dot{\mathrm{Q}}_{\mathrm{M}}}{\dot{\mathrm{Q}}_{\mathrm{F}}}=\left(\frac{\mathrm{L}_{\mathrm{M}}}{\mathrm{L}_{\mathrm{F}}}\right)^{5 / 2}$

Where, U, L and $\mathrm{Q}$ represent critical velocity, tunnel length and fire heat release rate, respectively and subscripts $\mathrm{F}$ and $\mathrm{M}$ indicate the model or full scale tunnel sizes.

In FDS, mesh size particularly when the computational domain involves with buoyant plume becomes an effective factor in the simulation results. This fact has been investigated in former studies [24-26]. Non-dimensional expression $\mathrm{D}^{*} / \delta \mathrm{x}$ is used as an indication factor to find a suitable mesh size, where $\delta \mathrm{x}$ is the nominal size of mesh and $\mathrm{D}^{*}$ is a characteristic fire diameter and can be calculated from the equation 6 [20].
$\mathrm{D}^{*}=\left(\frac{\dot{\mathrm{Q}}}{\rho_{0} \mathrm{~T}_{0} \mathrm{c}_{\mathrm{p}} \sqrt{\mathrm{g}}}\right)^{2 / 5}$

Where, $\dot{Q}$ is the heat release rate $(\mathrm{kW}), \mathrm{T}_{0}$ is the ambient temperature $(\mathrm{K}), \mathrm{C}_{\mathrm{p}}$ is the specific heat capacity of the air $(\mathrm{kJ} / \mathrm{kg} \mathrm{K}), \rho_{0}$ is the ambient air density $\left(\mathrm{kg} / \mathrm{m}^{3}\right), \mathrm{g}$ is the gravitational acceleration $\left(\mathrm{m} / \mathrm{s}^{2}\right)$.

According to the above mentioned approach and former studies [8, 19], a suitable mesh size for considered computational domains which involves fire was $0.25 \times$ $0.25 \times 0.25(\mathrm{~m})$.In the other sections the mesh sizes can be increased to maximum $0.5 \times 0.5 \times 0.5(\mathrm{~m})$ in order to reduce the calculation times. Tunnel wall has a boundary of convective heat transfer condition to the rock wall.

The ambient temperature is assumed $10{ }^{\circ} \mathrm{C}$ which is roughly average of reported temperature for referred experiments. An airflow boundary for entrance portal to create critical velocity and ambient pressure or open boundary condition for exit portal is applied. The tunnel length was $525 \mathrm{~m}$, and the regular cross section area and perimeter are shown in Figure 1. Fire boundary condition is located in the center of the tunnel. The heat release rate for calculations was proposed 29.1 and 20MW. As previously mentioned, these ranges of the fire loads were used to be able to compare the simulation and experimental outcomes using discussed scale laws from the other studies. A set of mean U-velocity measuring devices is located up and downstream at a distance of 100 and $200 \mathrm{~m}$ [10].

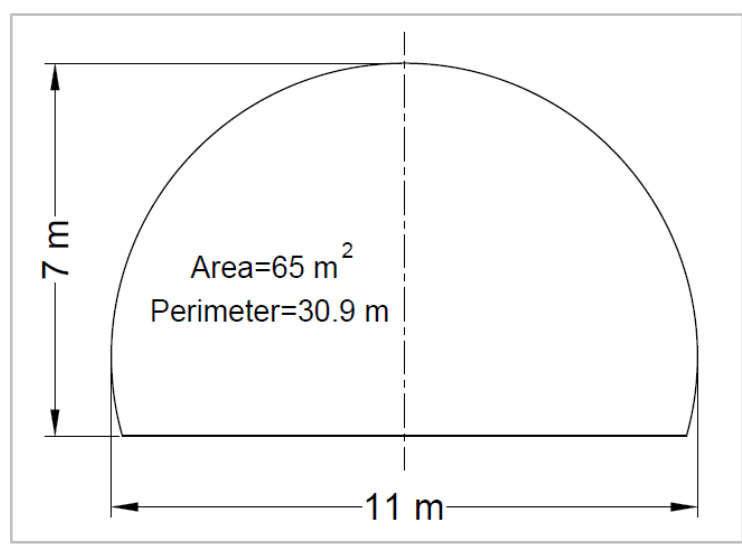

Figure 1. Tunnel cross section-full scale

\section{RESULTS AND DISCUSSION}

The critical velocity is calculated for 20 and $29.1 \mathrm{MW}$ fires from the equations 1 and 2 using same governing boundaries for considered full scale tunnel. The results of the calculations and its conversion to $1 / 10$ scale tunnel is shown in Table1. These calculations were done for downhill or negative longitudinal slopes $(\theta \leq 0)$.

The results of the calculations were used as a first estimation of velocity boundary condition for CFD simulations. As it is shown in Table1, the steady state critical velocities calculated from the simulations are $2.6-9.6 \%$ higher than the result of theoretical calculation. These ranges of the discrepancies are seen in the other experimental and numerical studies as well [13]. However, the achieved disagreement less than $10 \%$ and less than $6.3 \%$ with high frequency can be considered as an acceptable error for a numerical simulation. 
The steady state critical velocities with respect to the tunnel slope, for 20 and 29.1 MW heat release rate fires are shown in Figure 2 and Figure 3, respectively. The critical velocity does not show the same behavior in downhill and uphill gradients. Also, there is a small difference between dimensionless velocity correlation factor for 20 and $29.1 \mathrm{MW}$ fires. The dimensionless correlation factor between critical velocity and slope for 20 and 29.1MW fire loads can be expressed from a linear interpolation of data as equation 7 and 8 , respectively.

$\mathrm{u}_{\mathrm{cr}}=\mathrm{u}_{0}(1.0-0.020 \theta)$

$\mathrm{u}_{\mathrm{cr}}=\mathrm{u}_{0}(1.0-0.025 \theta)$

Where, $u_{\mathrm{cr}}$ is critical velocity for longitudinal slope of $\theta$ and $\mathrm{u}_{0}$ is the required critical velocity for $0 \%$ slope. In order to have only one equation, which roughly fits to both simulations, equations 7 and 8 can be rewritten as equation 9 .

$\mathrm{u}_{\mathrm{cr}}=\mathrm{u}_{0}(1-0.023 \theta)$

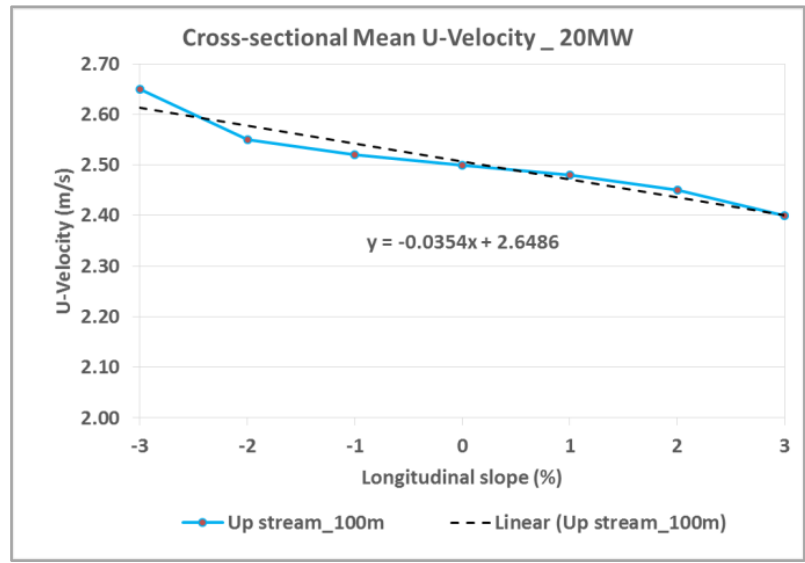

Figure 2. Upstream mean U-Velocity (critical velocity) steady state solution - 20MW

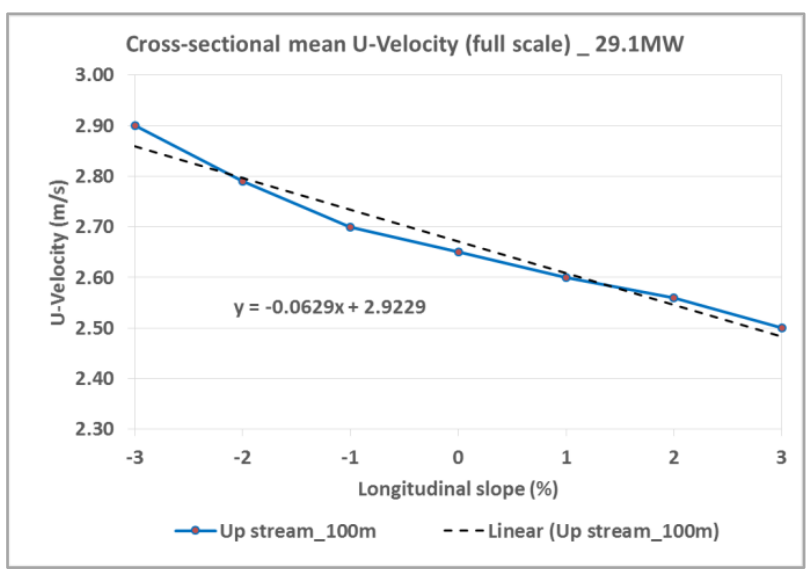

Figure 3.Upstream mean U-Velocity (critical velocity) steady state solution $-29.1 \mathrm{MW}$
As previously mentioned, in the referred experimental study, a model scale tunnel with scale of 1/10 was studied. The fire loads were 92 and $156 \mathrm{~kW}$ and ambient temperature was reported $4-14^{\circ} \mathrm{C}$ during the tests. The non-dimensional correlation factor between tunnel slope and critical velocity for mentioned experiments is shown in equation 10. As it is shown in Figure 4 and also equations 11, 12 and 13, the variation of the experimental results was higher comparing with the full scaled CFD simulation in this and also some other studies.

The discrepancies could be related to the velocity measuring accuracy, which in the referred experimental study was recorded as the average of the three specific points from cross section of the tunnel was recorded as critical velocity [10]. The critical velocity in the current numerical simulations was the steady state mean U-velocity which is measured in the tunnel cross section (averaged on the cross section). The fuel burning rate and combustion efficiency directly affects the heat release rate of the fire and whole process indirectly. Accordingly, another reason for the discussed variations (not only in the currently consider case, also in other studies (see Figure 4)) can be due to the prediction of the fuel burning rate and its efficiency in the pool fires. However, the result of this study shows good agreement with Danziger \& Kennedy [11] and Oka \& Atkinson works [16], as shown in Figure 4 and equation 12 , respectively.

$\mathrm{u}_{\mathrm{cr}}=\mathrm{u}_{0}(1-0.034 \theta)$

$\mathrm{u}_{\mathrm{cr}}=\mathrm{u}_{0}(1-0.023 \theta)$

The result of the current numerical study (equation 9), shows quite good agreement especially with equation 12 [1].

$\mathrm{u}_{\mathrm{cr}}=\mathrm{u}_{0}(1-0.022 \theta)$

Equation 13 gives another correlation factor between critical velocity and slope [16].

$\mathrm{u}_{\mathrm{cr}}=\mathrm{u}_{0}(1-0.014 \theta)$

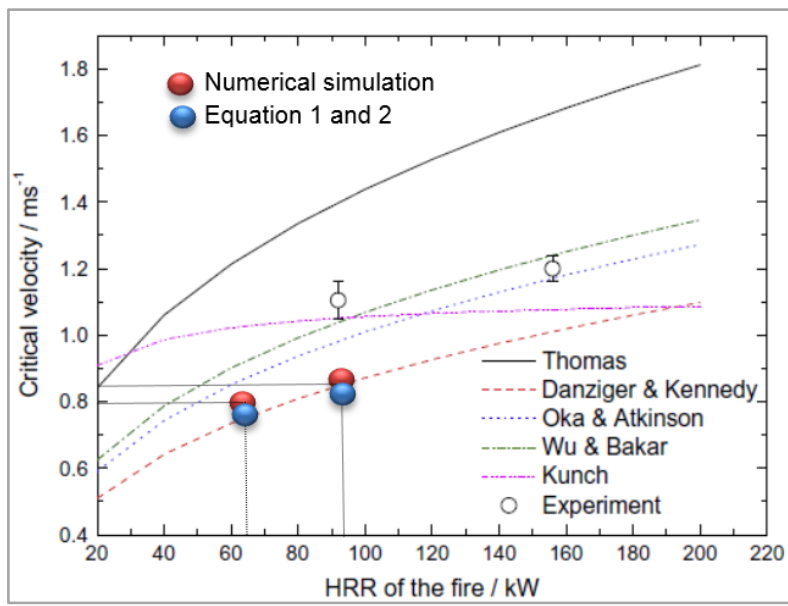

Figure 4.Comparison of the critical velocity values (green and blue points) with the other models [10] 
Table 1. Critical velocities for simulation and theoretical calculation- model and full scale

\begin{tabular}{|c|c|c|c|c|c|c|c|c|c|}
\hline \multirow{2}{*}{ No. } & \multirow{2}{*}{ Slope } & \multicolumn{2}{|c|}{$\begin{array}{c}\mathrm{u}_{\mathrm{cr}}(\mathrm{m} / \mathrm{s})- \\
\text { Equ.1\&2 }\end{array}$} & \multicolumn{2}{|c|}{$\mathrm{u}_{\mathrm{cr}}(\mathrm{m} / \mathrm{s})$ - FDS6 } & \multirow{2}{*}{$\begin{array}{l}\text { Discrepancy- } \\
\text { Equ.1\&2 and } \\
\text { FDS6 }\end{array}$} & \multirow{2}{*}{$\begin{array}{c}\text { Experimental } \\
(1 / 10) \\
\text { (Average) }\end{array}$} & \multirow{2}{*}{$\begin{array}{l}\text { HRR (MW) } \\
\text { Full scale } \\
(1 / 1)\end{array}$} & \multirow{2}{*}{$\begin{array}{l}\text { HRR }(\mathrm{KW}) \\
\begin{array}{c}\text { Model scale } \\
(1 / 10)\end{array}\end{array}$} \\
\hline & & $1 / 1$ & $1 / 10$ & $1 / 1$ & $1 / 10$ & & & & \\
\hline 1 & $-3 \%$ & 2.78 & 0.8791 & 2.90 & 0.9171 & $4 \%$ & 1.27 & 29.1 & 92 \\
\hline 2 & $-2 \%$ & 2.71 & 0.8570 & 2.79 & 0.8823 & $3 \%$ & $\sim 1.21$ & 29.1 & 92 \\
\hline 3 & $-1 \%$ & 2.63 & 0.8317 & 2.70 & 0.8538 & $2.6 \%$ & 1.105 & 29.1 & 92 \\
\hline 4 & $0 \%$ & 2.52 & 0.7969 & 2.65 & 0.8380 & $5 \%$ & 1.105 & 29.1 & 92 \\
\hline 5 & $1 \%$ & - & - & 2.60 & 0.8222 & - & 1.105 & 29.1 & 92 \\
\hline 6 & $2 \%$ & - & - & 2.56 & 0.8095 & - & $\sim 1.03$ & 29.1 & 92 \\
\hline 7 & $3 \%$ & - & - & 2.50 & 0.7906 & - & 1.035 & 29.1 & 92 \\
\hline 8 & $-3 \%$ & 2.5 & 0.7906 & 2.65 & 0.8380 & $6 \%$ & - & 20 & 63.25 \\
\hline 9 & $-2 \%$ & 2.45 & 0.7748 & 2.55 & 0.8064 & $4 \%$ & - & 20 & 63.25 \\
\hline 10 & $-1 \%$ & 2.37 & 0.7495 & 2.52 & 0.7969 & $6.3 \%$ & - & 20 & 63.25 \\
\hline 11 & $0 \%$ & 2.28 & 0.7210 & 2.5 & 0.7906 & $9.6 \%$ & - & 20 & 63.25 \\
\hline 12 & $1 \%$ & - & - & 2.48 & 0.7842 & & - & 20 & 63.25 \\
\hline 13 & $2 \%$ & - & - & 2.45 & 0.7748 & & - & 20 & 63.25 \\
\hline 14 & $3 \%$ & - & - & 2.4 & 0.7589 & & - & 20 & 63.25 \\
\hline
\end{tabular}

\section{CONCLUSIONS}

In this full scale numerical study, 14 set of simulations have been done in order to calculate the critical velocity in a sloping tunnel with high fire loads. For comparison, critical velocity was calculated through commonly used methods (equation 1 and 2). The result of the calculations from the mentioned equations and numerical simulations were compared with the model scale experiments using scale laws (equations 4 and 5). In a general expression, the results of the simulations were in good agreements with the theoretical calculations with an error of less than $10 \%$. The prediction of CFD simulation is slightly higher than calculation of equations $1 \& 2$ and this is confirmed by other studies [13]. The results of the numerically and theoretically calculated critical velocities showed remarkable variations compared to the referred experiments. But, comparing with the other studies (Figure 4), calculated correlation factor for critical velocity in the current study are in an acceptable range.

The other important possibility for comparison of the results is the currently used international standards for tunnel ventilation design [27-29]. For an example German guideline RABT 2006 for the tunnel equipment, recommends 2.5, 2.6 and $2.8 \mathrm{~m} / \mathrm{s}$ critical velocity for 30MW fire with longitudinal slope of 0 to $1 \%, 2$ to $3 \%$ and 3 to $6 \%$, respectively [29]. Therefore, the results of the numerical calculations are in acceptable range from the practical aspects as well.

\section{ACKNOWLEDGMENTS}

I would like to thank Prof. Sturm for valuable advices and IVT-Institute of Internal Combustion Engines and Thermodynamics (TU Graz) for support of FDS simulations.

\section{REFERENCES}

[1] W.K.Chow, Y.Gao, J.H.Zhao, J.F.Dang, C.L.Chow, L.Miao.2015. Smoke movement in tilted tunnel fires with longitudinal ventilation, Fire Safety Journal75 (2015)14-22.

[2] W.K. Chow, K.Y. Wong, W.Y. Chung. Longitudinal ventilation for smoke control in a tilted tunnel by scale modeling, Tunneling and Underground Space Technology 25 (2010) 122-128.

[3] L. Yi, J.L. Niu, Z.S. Xu, D.X. Wu. Experimental studies on smoke movement in a model tunnel with longitudinal ventilation, Tunneling and Underground Space Technology 35 (2013) 135-141.

[4] P. Lin, S.M. Lo, T. Li. Numerical study on the impact of gradient on semi-transverse smoke control system in tunnel, Tunneling and Underground Space Technology 44 (2014) 68-79. 
[5] L.H. Hua, L.F. Chen, L. Wu, Y.F. Li, J.Y. Zhang, N. Meng. An experimental investigation and correlation on buoyant gas temperature below ceiling in a slopping tunnel fire, Applied Thermal Engineering 51 (2013) 246254.

[6] Oka, Y., Atkinson, G.T., 1995. Control of smoke flow in tunnel fires. Fire Safety Journal. 25 (4), 305-322.

[7] Y. Wu, M.Z.A. Bakar. Control of smoke flow in tunnel fires using longitudinal ventilation systems - a study of the critical velocity, Fire Safety Journal 35 (2000) 363390

[8] Rafiei, Mehdi. Numerical simulation of a full scaled fire test of the tunnel with natural ventilation International Journal of Computer Applications, Volume 115 Number 1.

[9] H.Y.Wang. Numerical and theoretical evaluation of the fire propagation of smoke and fire in full-scale tunnel, fire safety journal 49 (2012) 10-21.

[10] Liang Yi, Qiqi Xu, Zhisheng Xu, Dexing Wu. 2014. An experimental study on critical velocity in sloping tunnel with longitudinal ventilation under fire, Tunneling and Underground Space Technology 43 (2014) 198-203.

[11] Danziger, N.H., Kennedy, W.D., 1982. Longitudinal ventilation analysis for the Glenwood canyon tunnels. In: Proceedings of the Fourth International Symposium Aerodynamics and Ventilation of Vehicle Tunnels, pp. 169-186.

[12] Thomas, P.H., 1968. The movement of smoke in horizontal passages against an air flow. Fire Research Note, No. 723, Fire Research Station, Watford, U

[13] C.C. Hwang, J.C. Edwards.2005, The critical ventilation velocity in tunnel fires-a computer simulation, Fire Safety Journal 40 (2005) 213-244.

[14] Karim Van Maele, Bart Merci.2008. Application of RANS and LES field simulations to predict the critical ventilation velocity in longitudinally ventilated horizontal tunnels, Fire Safety Journal 43 (2008) 598609.

[15] Ying ZhenLi, BoLei a, HaukurIngason.2010, Study of critical velocity and backlayering length in longitudinally ventilated tunnel fires, Fire Safety Journal 45 (2010) $361-370$

[16] G.T. Atkinson, Y.Wu, Smoke control in sloping tunnels, Fire Safety Journal 27(1996) 335-341.

[17] Kai Kang. Characteristic length scale of critical ventilation velocity in tunnel smoke control, Tunneling and Underground Space Technology 25 (2010) 205-211.

[18] Kang, K., 2006. Computational study of longitudinal ventilation control during an enclosure fire within a tunnel. Journal of Fire Protection Engineering 16 (3), $159-181$.

[19] Rafiei, M., Sturm, P.J. 2014. Influence of fires on-air velocity measurements at downstream measurement locations. 7th International Conference Tunnel Safety and Ventilation, Graz, Austria, pp. 265-272. ISBN: 9783-85125-320-7

[20] D. Stroup and A. Lindeman. Verification and Validation of Selected Fire Models for Nuclear Power Plant Applications. NUREG-1824, supplement 1, United States Nuclear Regulatory Commission, Washington, DC, 2013. 37.

[21] McGrattan, k., Hostikka, S., McDermott, R., Floyd, J.,Weinschenk, C., Overholt, K. Fire Dynamics Simulator User's Guide (Version 6.1.1). NIST Special Publication 1019 Sixth Edition; 2014

[22] Glenn P. Forney. Fire Dynamics Simulator Volume I: User's Guide (Version 6.1.11). NIST Special Publication 1017-1 Sixth Edition; 2014.

[23] McCaffrey, B.J., Quintiere, J.G., 1977. Buoyancy driven Countercurrent flows generated by fire source. In: Spalding, D.B., Afgan, N. (Eds.), Heat Transfer and Turbulent Buoyant Convection, Hemisphere Publishing Co., Washington, USA, pp. 457-472.

[24] S.B. Pope. Ten questions concerning the large-eddy simulation of turbulent flows. New Journal of Physics, 6:1-24, 2004

[25] L. Vervisch, P. Domingo, G. Lodato, and D. Veynante. Scalar energy fluctuations in Large-Eddy Simulation of turbulent flames: Statistical budgets and mesh quality criterion. Combust. Flame, 157:778 789, 2010.

[26] R. McDermott, G. Forney, K. McGrattan, and W. Mell. Fire Dynamics Simulator 6: Complex Geometry, Embedded Meshes, and Quality Assessment. In J.C.F. Pereira and A. Sequeira, editors, V European Conference on Computational Fluid Dynamics, Lisbon, Portugal, 2010. ECCOMAS.

[27] RVS 09.02.31 Tunnel Equipment, Ventilation - basic principles; FSV Working group tunnel, section operation and safety equipment, Vienna, Austria; version August 2008.

[28] RVS 09.02.32 Ventilation design - Fresh air demand, FSV Working group tunnel, section operation and safety equipment, Vienna, Austria; version June 2010.

[29] RABT (2006) German guideline for the equipment and operation of street tunnels, Forschungsgesellschaft für Straßen- und Verkehrswesen, Arbeitsgruppe Verkehrsführung und Verkehrssicherheit, May 2006. 